\title{
PALAVRA E IMAGEM
}

\section{Texto: Wendy Loyola}

llustração: Willi de Carvalho

("Poema do morro") e $J$

Rubber ("Frito")

Eu comecei a escrever poemas aos 8 anos, foi quando participe do Psiu Poético em minha terra natal, graças a Marli Froes, uma professora-poetisa que foi quem primeiro me incentivou.

De lá pra cá produzi poemas, peças, escrevi de uma maneira "clandestina" num blog na internet onde eu nutria um certo pânico de tornar minha escrita pública até receber o incentivo do Preta Poeta para publicar e declamar meus textos.

Durante as performances eu pude perceber a presença de um cosmologia diferente, que envolvia a todos numa espécie de "ritual coletivo", assim como ocorre em terreiros de candomblé, por exemplo.

Wendy Loyola é um nome, mas eu sou muitas. Na escrita eu encontro meus pedaços e pedaços de minhas ancestrais, nela eu resisto, me revejo, me reinvento, me reencontro, reconstruo meu afro-sertão. A escrita sem dúvida é o meu quilombo.

\section{aracadoagreste.blogspot.com}

Willi de Carvalho é artista atuante tambem em Belo Horizonte. Sobre sua filosofia de trabalho, ele afirma: "De rótulos referentes à minha obra, como 'neo barroco', 'contemporâneo' 'erudito', prefiro 'popular', mas isso não me interessa tanto. Arte é arte, livre de rótulos e classificações, o que me encanta é o entusiasmo e a emoção que as pessoas expressam frente ao meu trabalho."

\section{www.willidecarvalho.com.br}

J. Rubber é ilustradora e fotógrafa em Belo Horizonte. Sobre a ilustração, ela afirma: 'Ela [Wendy] me fez esse convite: ilustrar seu poema na revista Em Tese da UFMG. Puta responsabilidade que eu, como boa geminiana, dei uma bela esquivada de cara. que eu, como boa geminiana, dei uma bela esquivada de cara.
Mas ela colocou pilha. Ela mais uma vez acreditou em mim. Ela Mas ela colocou pilha. Ela mais uma vez acreditou em mim. acredita todo dia. E eu acredito nela. Esse amor é bem além vida."

www.instagram.com/j_rubber 


\section{"QUEM NÃO TEM AMIGo \\ MAS TEM UM LIVRO \\ TEM UMAESTRADA。" \\ CAROLINA MARIA DE JESUS}

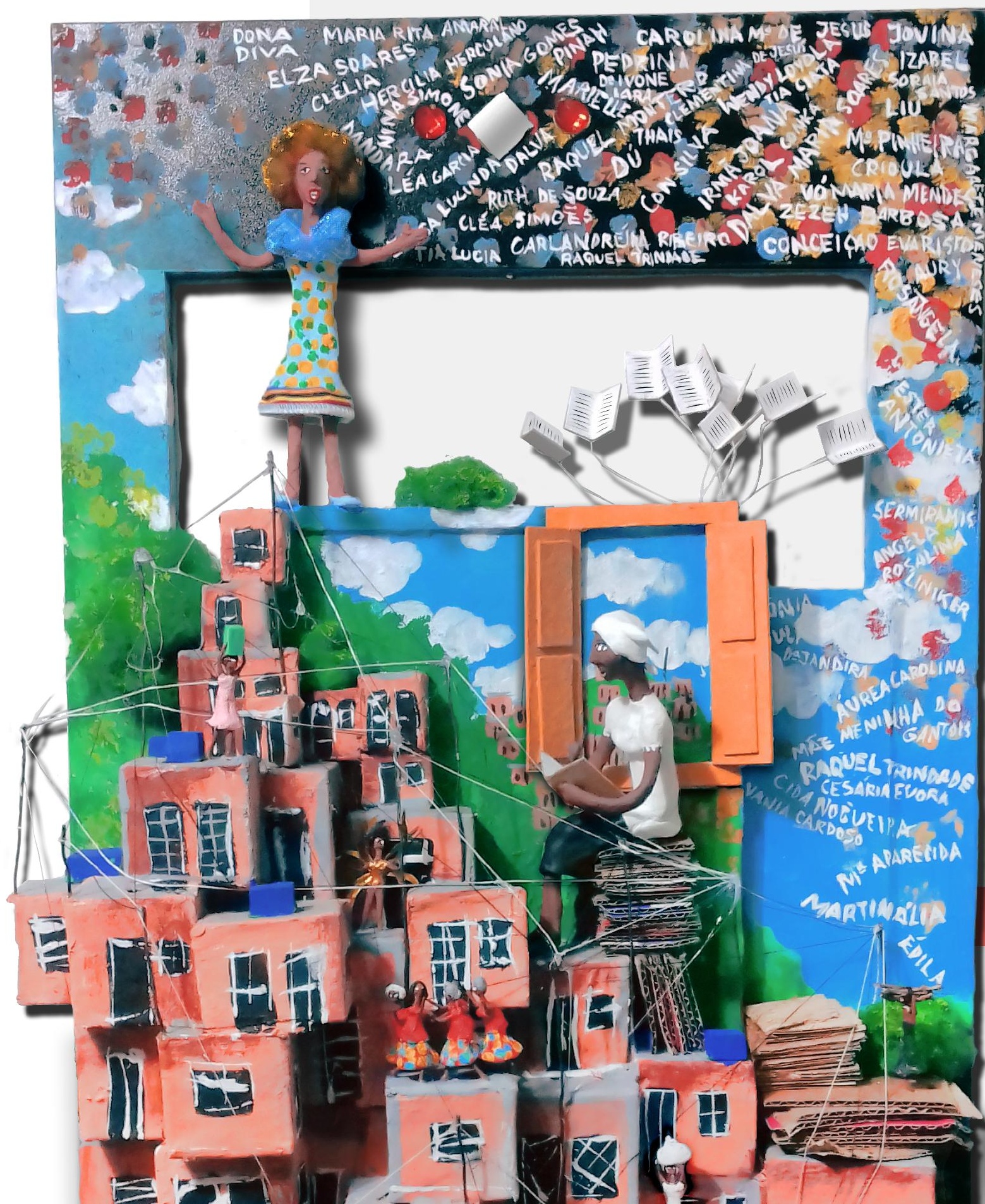

\section{POEMA DO MORRO}

$\mathrm{O}$ morro não gosta de dor:

O morro gosta de regar flor

na janela descascada sob os olhos dos animais sem raça

$\mathrm{O}$ morro não gosta de lamento;

O morro prefere dar exemplo

como Dona Carolina Maria de lenço ou como Conceição

[Evaristo

acordando todo dia com um sorriso

escondendo a lágrima de enterrar os filhos

O morro é o seu sacode, o seu eletrochoque,

o morro é o oposto do horror

e mede a ternura e ferve o medo na panela

$\mathrm{O}$ morro é o re-verso que liberta que sobe que ceifa que teima de manchar de sangue a vergonha dessa gente tacanha de gente que espera um tombo

O morro já estava sacando e permaneceu afrontando

na maledicência sorrindo e gingando

o corpo inclinado o morro virado de cabeça pra baixo

como um capoeira plantando bananeira

O morro fala mais alto que o amor de novela

e já não chora, já não sabe implorar 


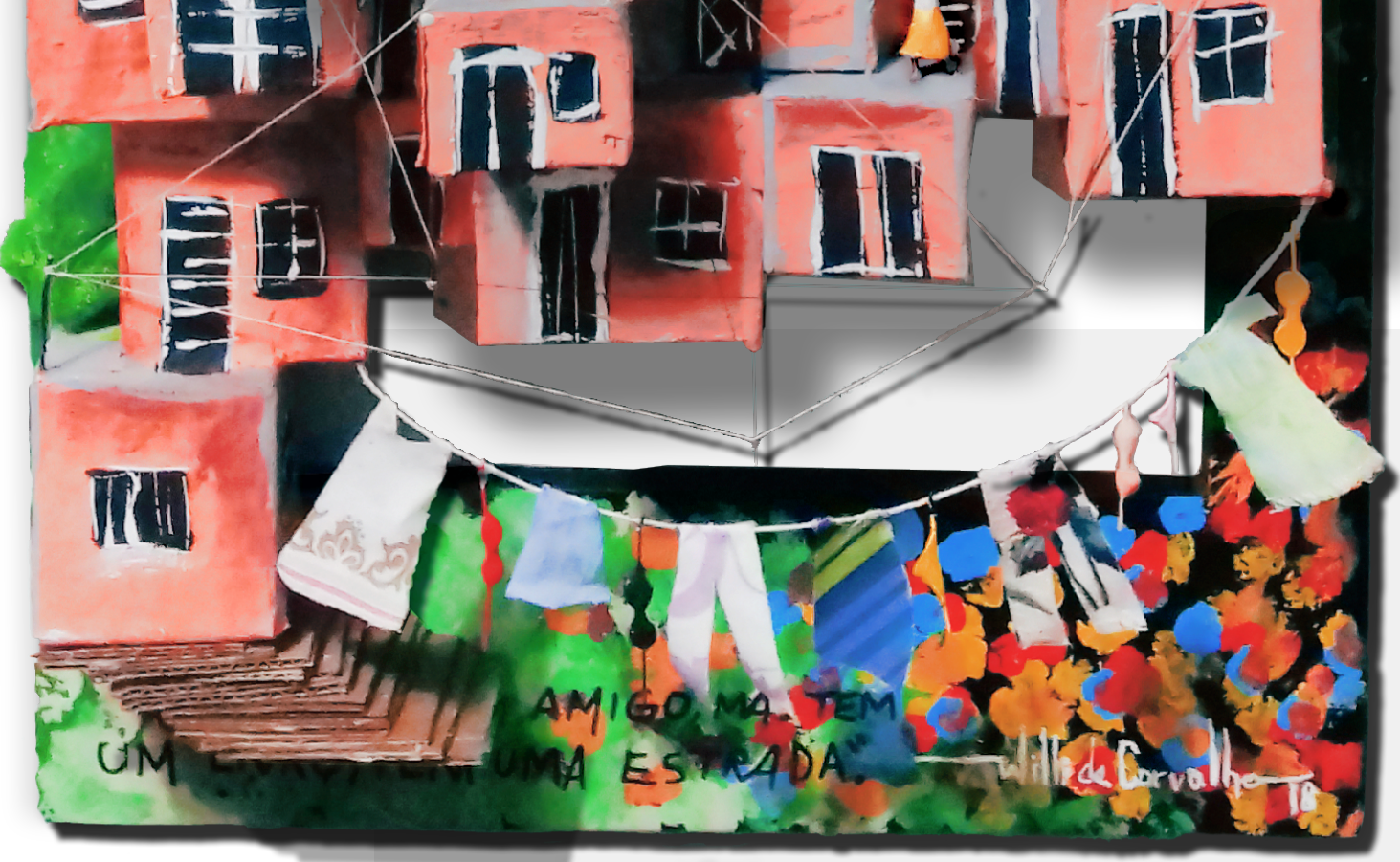

Passa um batom, calça um salto faz um samba dá ombros pra missa puritana

que gente sacana vem aqui rezar

pra se esconder da vergonha de ter

nas mãos a mancha. $\mathrm{O}$ morro procria o morro não cansa de resistir e lutar

O morro nunca vai morrer

Vai fazer um funk vai fazer um samba vai fazer um filho

e quem vai dormir sem um riso é você

O morro vai crescer pendurando barracos

como enfeites de natal numa árvore

O morro é o sorriso com dentes de prata dessa grande cidade

gargalhando da frieza dessa gente covarde

O morro é aquilo que eu subo por dentro

quando deixo o lamento e sinto o vento!

a paz de todas as estrelas

de todas as Marielles de todas as Tahnees Claudias e Elietes

Morro!

Mas não morro

O morro não pede socorro

quem pede socorro é você

que mata em nome do medo do morro, que dorme ao relento

e não tem como arma o tempo

o tempo que vamos vencer

Morro!

mas não morro

O morro descansa em paz

num mundo que pede socorro

já que a ternura jaz 


\section{FRITO}

Frito um ovo

Frito torrêmo

Frito peixe frito

Frito french fries

Acabou eu frito mais

Vou fritando pra não ir fervendo

Eu fervendo? Nem fodendo!

Frito camarão no dendê pra despacho

Só não frito a cabeça por causa de macho

Ah, meu bem, isso eu não faço!

Não nasci pra ser capacho.

Coesse papo de ciúme, recla mação, fritação,

lambeção de saco

Me erra, diacho!

- Frito mais pelo o jornal

que me arremessa a cabeça na página policial

"homem incendeia mata esposa e 2 duas filhas "

"uma delas foi encontrada no guarda roupas da família"

O motivo é sempre torpe: fim do relacionamento

Provavelmente mais uma que tentou dar um passo em

prol da própria vida

Com ciúme, amor de novela, onde eu sou a refém que

espera: não perco meu tempo

Enquanto a minha cabeça estiver na bandeja todo o dia 
"pai carboniza filha de 2 anos"

enquanto meu corpo estiver fragilizado, exposto

"homem mata esposa com 17 facadas, 5 no rosto"

enquanto eu perder o direito à vida não tenho mais nada

"homem estupra e mata enteada"

enquanto a minha independência emocional e financeira

for um risco

"homem invade o salão da esposa e a mata com 3 tiros".

eu prefiro aquele a mor proibido

Por mim mesma

Sabe aquele amor que dispara o coração, cheio de peri-

gos, pernas bambas, amor bandido da mocinha que nun-

ca pode encontrar totalmente objeto de desejo?

Seja!

"uma mulher tem qualquer coisa que chora, qualquer

coisa que sente saudade, feita pra amar e ser só perdão"

Não, Seu Vinícius, não

Uma mulher tem qualquer coisa que morre em página

policial , qualquer coisa que luta

Feita para gozar, resgatar seus próprios territórios, man-

dar no seu próprio corpo

E ser o que ela quiser. 